\title{
The competitive effect of Electro-chlorination over chlorination for controlling disinfection by-product formation in phenol and aniline enriched groundwater
}

\section{Vijay Laxmi Mohanta}

Indian Institute of Technology (Indian School of Mines): Indian Institute of Technology

Brijesh Kumar Mishra ( $\sim$ brijesh@iitism.ac.in )

Indian Institute of Technology (Indian School of Mines): Indian Institute of Technology https://orcid.org/0000-0002-4451-1924

\section{Research Article}

Keywords: Electro-chlorination, Disinfection By-products, Health Risk Assessment, Organic pollutant, Groundwater

Posted Date: August 9th, 2021

DOI: https://doi.org/10.21203/rs.3.rs-791204/v1

License: (c) (1) This work is licensed under a Creative Commons Attribution 4.0 International License.

Read Full License 
The competitive effect of Electro-chlorination over chlorination for controlling disinfection by-product formation in phenol and aniline enriched groundwater

\author{
Vijay Laxmi Mohanta and Brijesh Kumar Mishra* \\ Department of Environmental Science and Engineering \\ Indian Institute of Technology (Indian School of Mines), Dhanbad-826004, India \\ *Corresponding Author; E-mail: brijesh@iitism.ac.in Contact Details: +91-9471191704
}

\title{
Abstract:
}

Disinfection is an essential step to keep humans healthy from microorganisms present in drinking water. However, the formation of disinfection by-products (DBPs) is associated with adverse health effects, and the presence of organic pollutants in groundwater results in even more detrimental effects. Therefore, a better treatment technique is required to disinfect and remove organic pollutants simultaneously to control the formation of DBPs. Electrochlorination (EC) was carried out using graphite electrode at the current density of 0.54-1.09 $\mathrm{mA} / \mathrm{cm}^{2}$ and sodium chloride for in-situ hypochlorite generation to treat groundwater contaminated with phenol and aniline. The comparative study between chlorination and EC showed a significant level of oxidation of phenol and aniline, resulting in their reduction up to $98.48 \%$ and $99.47 \%$, respectively, in the EC process. Due to the higher mineralization rate of aniline, both chlorination and EC method are found to be effective. However, only the EC method is found to be appropriate and effective for treating phenol-contaminated water as the chlorination method resulted in the formation of complicated phenolic by-products. GasChromatography/Mass-Spectrometry (GCMS) was used to assess the by-product formation of chlorination and EC in contaminated groundwater through the full-scan.

Keywords: Electro-chlorination; Disinfection By-products; Health Risk Assessment;

\section{Organic pollutant; Groundwater}




\section{Introduction}

The existence of anthropogenic organic contaminants in groundwater has been the subject of profound studies in recent years worldwide. Anthropogenic organic pollutants in surface water, sewage and groundwater, and potable water have been identified as contaminants (Postigo and Barceló 2015; Lapworth et al., 2015). Pesticides and pharmaceuticals with metabolite, steroid, industrial additive, hormone, water treatment by-products, personal care products, fire retardants, and food additives are the most prominent of these pollutants (Stuart et al., 2012). Several of them may have a detrimental effect on human health and the environment, emphasizing that they need to consider their environmental role more effectively. In addition, coke-based factories are deemed responsible for generating large amounts of wastewater containing extremely hazardous, mutagenic as well as carcinogenic contaminants, including phenol and aniline (USEPA 2012; Mohanta and Mishra 2020). Because of its life-form solid toxicity, chemical uncertainty, high water-solubility, and volatility, the US Environmental Protection Agency (USEPA) recognizes them as its priority contaminants. They are also vulnerable to subsurface propagation and pose a significant health hazard that can affect the cardiovascular system, neurological processes, and even kidney failure (Wen et al. 2015; USEPA 2014; Mustapha et al., 2020; Mohanta and Mishra 2020).

As per Central Pollution Control Board (CPCB), usually, groundwater doesn't need advanced treatment processes unless harmful pollutants are present in it, unlike surface water which is typically susceptible to higher contamination and an advanced treatment process is mandatory. Mostly, only disinfection is done in groundwater to kill pathogens present in them. Chlorination, due to its efficacy and affordability, is the most popular form of disinfection of groundwater. However, groundwater contaminated with organic pollutants requires more disinfection effective techniques due to the formation of several regulated and unregulated DBPs in conventional chlorination techniques (Richardson and Postigo 2015; Dong et al., 
2018). Pan and Zhang (2013) identified four new groups of aromatic halogenated DBPs, which can be decomposed to form trihalomethanes (THMs) and haloacetic acids (HAAs) while chlorinating drinking water. Their formations are highly influenced by $[\mathrm{HOBr}] /[\mathrm{HOCl}]$. The presence of natural organic matter (NOM) with high aromatic content is responsible for aromatic halogenated DBPs. Ding et al., (2013) has identified occurrence patterns of 28 DBPs, including THMs, HAAs, haloacetonitriles (HANs), and emerging iodinated THMs (i-THMs) in the treated water, which was found to be cytotoxic and genotoxic in nature.

To overcome these problems, a treatment technique is needed that will treat the organic loading as well as disinfect the water at the same time. Many scientists currently concentrate on electrochemical processes to oxidize organic pollutants, and the literature shows that the Electrochemical method individually is not economical; therefore, several organic contaminant oxidization electrolytes have been tested. Electrochemical oxidation methods are used by various researchers for successfully disinfecting drinking water depending upon electrolyte solution and ability to produce radicals by different electrodes such as boron-doped diamond (BDD), dimensionally stable anode (DSA), platinum, and hemin/graphite (Jeong et al., 2007, 2009; Maa et al., 2011). Electro-oxidation may occur either by direct oxidation by hydroxyl radicals produced on anode's surface or by an indirect process where oxidants like chlorine, hypochlorous acid, and hypochlorite are formed at the electrode (Särkkä et al., 2015). Hypochlorite as an electrolyte can be used in the electrochemical treatment of groundwater polluted with organic loading as it is the most potent oxidizing agent of the chlorine oxyanions (Singh et al., 2021). However, hypochlorite handling and storing is a complex operation, making it costlier to use and more challenging to store. Therefore, it should be generated onsite through the Electro-chemical process, using sodium chloride, which is readily available and very cost-effective (Key 2010). Negatively charged ions, such as hydroxyl, oxygen, and chloride ions, donate electrons at the anode to produce oxygen gas, chlorine dioxide, 
hypochlorous acid, hypochlorite ion, and hydrochloric acid under direct current (DC) voltage.

76

77

78

79

80

87 Advanced Electro-oxidation techniques encourage complete mineralization of toxic organic

Positively charged ions, on the other hand, such as hydrogen, calcium, magnesium, sodium, and potassium ions, gain electrons at the cathode and form hydroxide and hydrogen gas (Ashokan and Subrmaniyan 2009; Yi et al., 2019).

Anode :

$$
2 \mathrm{Cl}^{-} \leftrightarrow \mathrm{Cl}_{2}+2 e^{-}\left(E_{o}=1.36 \mathrm{~V}\right)
$$

Bulk Solution : $\quad \mathrm{Cl}_{2}+\mathrm{H}_{2} \mathrm{O} \rightarrow \mathrm{H}^{+}+\mathrm{Cl}^{-}+\mathrm{HOCl}$

$$
\begin{aligned}
& \mathrm{HOCl} \leftrightarrow \mathrm{OCl}^{-}+H^{+}\left(\mathrm{pK}_{a}=7.5 \text { at } 25^{\circ} \mathrm{C}\right) \\
& \mathrm{HOCl}+\mathrm{OCl}^{-}+\mathrm{H}^{+}+e^{-} \leftrightarrow 1 / 2 \mathrm{Cl}_{2}+\mathrm{H}_{2} \mathrm{O}\left(E_{o}=1.63 \mathrm{~V}\right) \\
& \mathrm{NaCl}+\mathrm{H}_{2} \mathrm{O} \rightarrow \mathrm{NaOCl}+\mathrm{H}_{2}
\end{aligned}
$$

Cathode : $\quad \mathrm{O}_{2}+2 e^{-}+2 \mathrm{H}^{+} \rightarrow \mathrm{H}_{2} \mathrm{O}_{2}\left(E_{o}=0.68 \mathrm{~V}\right)$

$$
2 \mathrm{H}_{2} \mathrm{O}+2 e^{-} \rightarrow 2 \mathrm{OH}^{-}+\mathrm{H}_{2}
$$

pollutants in simpler forms, i.e., $\mathrm{CO}_{2}$, water, and inorganic compounds (Karthikeyan et al., 2014).

The study aims to find a suitable and effective disinfection process that can treat microorganisms and organic pollutants in groundwater by controlling the formation of DBPs.

\section{Materials and Methods}

\subsection{Collection and characterization of groundwater samples}

94 Standard sampling protocols were used to collect and preserve groundwater samples in triplicates from a dug-well near a steel industry, Asansol, West Bengal, India, using the grab 
sampling method (Neilsen and Neilsen 2006). Water samples were preserved in prewashed

97 polypropylene bottles and stored at $4{ }^{\circ} \mathrm{C}$. Aniline and phenol concentrations were determined

98 by UV/Vis Spectrophotometer at the absorbance $555 \mathrm{~nm}$ and $500 \mathrm{~nm}$ respectively for samples

99 before and after the disinfection process (Norwitz and Kellher, 1981; APHA 2017).

\subsection{Risk estimation of water sample before and after treatment}

The human health risk was estimated due to exposure to aniline and phenol-contaminated groundwater using USEPA 2005 method. Chronic daily intake (CDI) was evaluated as per IRIS 2009 in $\mathrm{mg} / \mathrm{kg}$-d for aniline and phenol by ingestion exposure route. Input parameters were adapted from the study on risk by Mohanta and Mishra, 2020.

$$
C D I_{\text {Oral }}=\frac{C_{w} \times I R \times E F \times E D}{B_{w} \times A T}
$$

106

$C D I_{\text {Dermal }}=\frac{C_{w} \times S A \times P C \times F \times E T \times E F \times E D}{B_{w} \times A T}$

107

$$
C D I_{\text {inhalation }}=\frac{C_{\text {air }} \times V R \times A E \times E T \times E F \times E D}{B_{w} \times A T}
$$

$\mathrm{C}_{\text {air }}$ was calculated by following equations proposed by Little's theory in terms of concentration of phenol and aniline in the bathroom (Mishra et al., 2014);

$$
C_{a i r}=\frac{Y_{s(t)}+Y_{s(i)}}{2}
$$

Ys(i) is the initial phenol and aniline concentration in the shower room (assumed as $0 \mathrm{mg} / \mathrm{L}$ ),

$113 \mathrm{Ys}(\mathrm{t})$ is the phenol and aniline concentration in the shower room at time $\mathrm{t}$ (mins).

$$
Y_{s(t)}=\left[1-e^{-b t}\right] \times \frac{a}{b}
$$


$a=\frac{Q_{L} \times C_{w}\left(1-e^{-N}\right)}{V_{s}}$

$116 \quad b=\frac{\left[\frac{Q_{L}}{H} \times\left(1-e^{-N}\right)\right]+Q_{G}}{V_{s}}$

117

$N=\frac{K_{O L} A}{Q_{L}}$

118 Whereas $\mathrm{N}$ is a dimensionless coefficient,

$119 \mathrm{Q}_{\mathrm{L}}=$ Water flow rate in $\mathrm{L} / \mathrm{min} ; \mathrm{a}=$ factor; $\mathrm{b}=$ factor; $\mathrm{t}=$ time of contact in $\min$

120 Hazard Quotient (HQ) represents the non-cancer risk in humans. HQ for all the routes of

121 exposure due to aniline and phenol contaminated groundwater was calculated according to the

122 following formulas:

$123 H Q_{\text {Oral }}=C D I / R f D_{\text {Oral }}$

124

$H Q_{\text {inhalation }}=C D I / R f C$

125

$T H Q=H Q_{\text {oral }}+H Q_{\text {dermal }}+H Q_{\text {inhalation }}$

126 Where THQ stands for Total Hazard Quotient, which is defined as the sum of hazard quotients

127 due to all three routes of exposure. RfD value (Reference dose) for phenol and aniline is taken 128 as $0.3 \mathrm{mg} / \mathrm{kg}$-day and $0.00688 \mathrm{mg} / \mathrm{kg}$-day respectively. The $\mathrm{RfC}$ (Reference concentration) for 129 phenol and aniline is taken as $0.2 \mathrm{mg} / \mathrm{m}^{3}$ and $0.001 \mathrm{mg} / \mathrm{m}^{3}$ respectively (RSL 2016).

130 According to USEPA, the threshold limit is considered as 1 for HQ (Mohanta et al., 2020).

$131 \quad$ 2.3.Chlorination and Electro-chlorination process

132 A comparison study was done to identify the suitable and effective method for chlorinating 133 aniline and phenol-contaminated groundwater. The chlorine demand of the raw water sample 
was calculated using the Iodometric method (4500-Cl, APHA 2017). The emergence of DBPs is allied to the elevated level of residual chlorine; therefore, regulation of available and residual chlorine needs to be done (Otter et al., 2020). In chlorination, estimated chlorine dosing of 1.8 $\mathrm{mg} / \mathrm{L}$ was done (i.e., $1.6 \mathrm{mg} / \mathrm{L}$ Chlorine demand $+0.2 \mathrm{ppm}$ residual chlorine) and mixed thoroughly, which was then left for a contact period of 30 minutes in an open vessel.

In this study, EC has been executed to avoid the formation of chlorinated by-products, and its laboratory setup is shown in fig 1 . The electrochemical remediation of phenol and aniline contaminated groundwater was carried out as batch type in a plexiglass reactor having a specific dimension of $(160 \times 120 \times 120) \mathrm{mm}$. The distance amongst graphite electrodes was held at $25 \mathrm{~mm}$ based on the preliminary optimization. Throughout the procedure, the anodic surface area immersed in the solution was $110 \mathrm{~cm}^{2}$. A precision DC power source was used (PowerPac ${ }^{\mathrm{TM}} \mathrm{HC}$ power supply Bio-Rad laboratories the USA, model no. 164-5052), and the applied current was set between 60 to $120 \mathrm{~mA}$, contributing to a current density of $0.54-1.09$ $\mathrm{mA} / \mathrm{cm}^{2}$. Based on the stoichiometry, the chlorine dosing was done in the form of $2.96 \mathrm{mg} / \mathrm{L}$ sodium chloride, contributing to $1.8 \mathrm{mg} / \mathrm{L}$ chlorine (i.e., $1.6 \mathrm{mg} / \mathrm{L}$ Chlorine demand $+0.2 \mathrm{mg} / \mathrm{L}$ residual chlorine) for a total contact period of 30 minutes. The concentrations of aniline and phenol were measured after that for both cases.

151 Fig 1. Schematic diagram of the electro-chlorination setup.

\subsection{Calculation and energy consumption}

153 As a function of electrolysis duration, the \% removal efficiency of chlorination and EC for all 154 contaminants was calculated using Eq. 19.

$155 \eta \eta=\frac{C_{o}-C_{t}}{C_{o}} \times 100$ 
Where $\mathrm{C}_{0}$ and $\mathrm{C}_{\mathrm{t}}$ are the initial and residual concentrations of phenol and aniline at times 0 and $\mathrm{t}$, respectively.

158 In the electrochemical process, the quantity of energy consumed, which is a crucial economic parameter, was estimated according to Eq. 20.

$160 \quad E=\frac{U \times I \times T}{V}$

161 Where E represents the electrical energy consumed (in $\mathrm{kWh} / \mathrm{m}^{3}$ ); $\mathrm{U}$ is the voltage applied (in

162 Volt); $\mathrm{I}$ is the current (in Ampere); $\mathrm{T}$ is the electrolysis time (in hours), and $V$ is the volumes 163 (in litres).

\subsection{Analysis of By-product formation using GC-MS}

165 To analyze the organic by-product formation due to chlorination and EC of all the samples, including raw water, Gas chromatography-mass spectrometry (GCMS) analysis was carried out. The organic compounds were extracted in the solvent dichloromethane using EPA 8270 method through the liquid-liquid extraction ion method (EPA 8270, 2018). The samples were then concentrated by evaporating in a water bath at 38 to $41^{\circ} \mathrm{C}$, further concentrated using the 170 nitrogen blowout technique.

171 These extracted samples were then analyzed through GCMS by a TG-5MS $(30 \mathrm{~m} \times 0.25 \mu \mathrm{m})$ GC column in GC (Thermo Fisher trace 1300) with TSQ Duo mass spectrometer equipment, under the operating condition of the standard EPA method. The oven temperature of $100^{\circ} \mathrm{C}$ was applied and then increased to $290^{\circ} \mathrm{C}$ after 2 minutes, with a ramp rate of $5^{\circ} \mathrm{C}$. Other analytical conditions are as follows; Injection temperature $-250^{\circ} \mathrm{C}$; Solvent delay- $2 \mathrm{~min}$, and electron energy was $70 \mathrm{eV}$. Measurement mode: Scan; Mass range: m/z 50-550 and total run time $60 \mathrm{~min}$. The carrier gas was pure helium $(99.999 \%)$ at a $1.1 \mathrm{~mL} / \mathrm{min}$ flow rate.

\section{Results and discussions}




\subsection{Effect of chlorination and electro-chlorination in aniline and phenol concentration}

In the raw groundwater sample, the aniline and phenol concentrations were found to be 0.34 and $0.271 \mathrm{mg} / \mathrm{L}$, respectively, which is 58.4 and 292 times higher than the desired limit in drinking water (IS: 10500, 2012; ATSDR 2002). For EC, sodium chloride was chosen for onsite generation of Sodium hypochlorite, which is approximately 5.08 times cheaper than using it as chlorination dosing (Key 2010). An optimization study was done primarily, and it was found that the current density of $0.818 \mathrm{~mA} / \mathrm{cm}^{2}$ resulted in maximum removal of aniline. In comparison, maximum phenol removal from contaminated groundwater was achieved at a current density of $0.91 \mathrm{~mA} / \mathrm{cm}^{2}$. The amount of maximum electrical energy consumed for maximum reduction of phenol and aniline was estimated to be $1.35 \mathrm{kWh} / \mathrm{m}^{3}$ and $1.51 \mathrm{kWh} / \mathrm{m}^{3}$, respectively. Residual chlorine after chlorination and EC process was assessed and found to be $1.9 \mathrm{mg} / \mathrm{L}$ and $2.1 \mathrm{mg} / \mathrm{L}$, respectively, therefore meeting the regulations for residual chlorine in portable water.

In chlorination, aniline and phenol concentrations were reduced by $92.35 \%$ and $6.27 \%$, respectively. The very low removal efficiency of total phenol was achieved due to the formation of several phenol-based chlorination by-products such as 2-Oxo-4-phenyl-6-(4chlorophenyl)-1,2-dihydropyrimidine, 5-chloro-4,6-diphenyl-, 2,3,4,6-tetrachlorophenyl ester, etc. The formation of chloro-phenols due to the chlorination of phenols present in the water was also reported by Jiang et al., (2020). While, in the case of electro- chlorination, removal efficiencies of $99.47 \%$ and $98.48 \%$ were achieved for aniline and phenol concentrations, respectively, because of their oxidation into simpler forms. Pillai and Gupta (2016) also attained more than $99 \%$ phenol removal efficiency using $\mathrm{NaCl}$ as an electrolyte at all $\mathrm{pH}$ ranges. It clearly suggests lesser by-product formation in the EC process than that of conventional chlorination methods, making it an environmentally friendly and sustainable technology (Yi et al., 2019). The in-situ production of hypochlorite due to electrolysis of $\mathrm{NaCl}$ 
may initially result in the formation of p-chlorophenol, which will assist in a higher degradation rate of phenol, as its degradation rate is much higher than phenol (Sathish and Vishwanath 2005). phenol degradation exhibits pseudo-first-order kinetics, and the indirect oxidation of active chlorine at anode enhances the degradation and mineralization, resulting in their removal through electrochemical oxidation of chlorine (Tasic et al., 2014; Villegas et al., 2016; Tawabini et al., 2020). The degradation rate of phenol is reported to be faster in an alkaline medium, and its proposed possible pathway is shown in figure 2. Sathish and Vishwanath 2005 have reported a similar decomposition pathway for phenol in alkaline medium.

Fig 2. Removal efficiencies of phenol and aniline at a different applied current

Fig 3. Pathway for decomposition of phenol during Electrolysis with $\mathrm{NaCl}$ as electrolyte

\subsection{Human Health Risk assessment for Chlorinated and Electro-chlorinated} groundwater

Exposure to aniline and phenol-contaminated groundwater may result in various health hazards, including damage to the cardiovascular and neurological systems. To assess the extent of risks to human health, Hazard Quotient was evaluated before and after the chlorination process, as shown in table 1. HQ due to phenol contaminated groundwater via ingestion route of exposure was found to be $0.055,0.049,0.06$ for men, women, and children, respectively. Lower HQ values were due to the high $\mathrm{RfD}$ value of phenol, i.e., $0.3 \mathrm{mg} / \mathrm{Kg}$-day. $\mathrm{HQ}$ via dermal and inhalation routes of exposure was found to be very low, i.e., up to $2.55 \mathrm{E}-04$ and 2.50E-06, respectively, therefore contributing negligible weightage to the total hazard quotient. In the case of chlorination, there was an insignificant reduction in $\mathrm{HQ}$, while a considerable reduction was observed compared to the electro-chlorinated water sample. Many phenolic compounds with complicated structures were present in the raw water. Simple chlorination resulted in the formation of even more complex by-products of phenolic compounds. However, 
in the EC process, these compounds were dissociated into simpler forms, resulting in a drastic reduction of phenol content. THQ due to aniline contaminated groundwater was found to be $3.08,2.73$, and 3.33 for men, women, and children, respectively. High HQ value even for lower aniline concentration was due to its lower Reference dose (RfD) value, i.e., $0.0068 \mathrm{mg} / \mathrm{Kg}$-day, representing a higher probabilistic non-cancer risk to the exposed population. However, a remarkable reduction in HQ was observed in the case of both the chlorination and EC process (table 1). In chlorinated water, THQ was found to be 2.35E-01, 2.09E-01, and 2.55E-01, while for $\mathrm{EC}$ water, it was found to be $1.63 \mathrm{E}-02,1.44 \mathrm{E}-02$ and $1.77 \mathrm{E}-02$ for men, women and children, respectively. It was evident that for aniline, any treatment method can be used due to its higher mineralization rate. Although the THQ values were reduced for Phenol and Aniline contaminated water after chlorination, but still, the formation of toxic DBPs will lead to considerable carcinogenic and non-carcinogenic risks. For all the cases, it was observed that children were at the highest non-cancer risk due to their lower body weight concerning ingestion rate (Laxmi Mohanta et al., 2019, Mohanta and Mishra 2020).

Table 1: Hazard Quotient of water samples before and after chlorination.

\subsection{Analysis of by-product formation by GC-MS}

The organic compounds in the raw and treated groundwater were studied and calculated using the mass spectral library database of the National Institute of Standards and Technology (NIST)

(Fig 3). The results showed that organic pollutants found in groundwater were evidently degraded, and only Decanedioic acid was found in abundance in EC treated water, which is neither toxic nor hazardous in nature. Phenol was found in all the samples; however, its relative abundance was found to be negligible in the case of EC treatment. Many new by-products such as 2-Hydroxybiphenyl, 2,3,4,6-tetrachlorophenyl ester, 6-Fluoro-2-trifluoromethylbenzoic acid, 
252 Hydroxybiphenyl, 2-Oxo-4-phenyl-6-(4-chlorophenyl)-1,2-dihydropyrimidine, etc were 253 formed in chlorination process (Table 2). In the EC process, phenol present in the water sample 254 was converted into a carboxylic acid, carbon dioxide and water, as shown in fig 2, and was 255 found at the low relative abundance in the form of 1,4-Benzenedicarboxylic acid. Some of 256 these compounds are corrosive, toxic and may cause environmental as well as health hazards. 257 Aniline was present in the form of 2-Chloroaniline-5-sulfonic acid in raw water; however, it was not identified in the chromatograms of both the treated groundwater due to its higher mineralization rate into the end product and intermediate products (Singh et al., 2021).

Fig. 4: GC-MS analysis chromatograms (a) Raw groundwater (b) chlorinated water (c) electrochlorinated water

Table 2. GC-MS Analysis of groundwater treated using chlorination and electro-chlorination

\section{Conclusion}

This study focused on evaluating an effective treatment technique that will disinfect the groundwater as well as oxidize the organic pollutants such as phenol and aniline at the same time by controlling the formation of DBPs. The comparative study between chlorination and EC process with respect to oxidation of phenol and aniline and by-product formation showed profound results. HQ due to phenol in groundwater showed negligible reduction for chlorination, which resulted in the formation of a number of complicated by-products. In contrast, the drastic reduction was observed in the case of EC as its degradation and mineralization system efficiency was enhanced by indirect oxidation of chloride ions formed at the anode. However, HQ due to aniline reduced significantly for both the chlorination and election-chlorination, because of its higher mineralization rate. Several harmful chlorination and other by-products formations were observed in the case of chlorination, making the contaminated groundwater even more toxic to consume. However, only one non-toxic by- 
product, i.e., Decanedioic acid was found in the case of EC. If the only aniline is present in

277 groundwater, both chlorination and election-chlorination can be opted. However, if phenol is

278 present, then EC is found to be effective and safe for human health. Further detailed study may

279 also be needed for quantitative study of DBPs formation and associated risks.

280 Acknowledgment

281 The authors would like to acknowledge the Indian Institute of Technology (Indian School of 282 Mines), Dhanbad, India, for providing research and financial facilities.

283 Declaration of competing interest

284 The authors declare that they have no known competing financial interests or personal 285 relationships that could have appeared to influence the work reported in this paper.

286 References:

287 APHA (American Public Health Association) (2017). Standard Methods for the examination 288 of water and wastewater. In 23rd Edit, American Public Health Assoc, American Water Works 289 Assoc, Water Pollution Control Federation, Water Environment Federation, Washington DC.

290 ATSDR (2002). Agency for Toxic Substances and Disease Registry. Aniline fact sheet 2002.

$291<$ http://www.atsdr.cdc.gov/tfacts171.pdf> (May 25, 2011). Retrieved on 2 August 2019.

292 Asokan, K., \& Subramanian, K. (2009, October). Design of a tank electrolyzer for in-situ 293 generation of $\mathrm{NaClO}$. In Proceedings of the World Congress on Engineering and Computer Science (Vol. 1, pp. 139-142).

295 Ding, H., Meng, L., Zhang, H., Yu, J., An, W., Hu, J., \& Yang, M. (2013). Occurrence, 296 profiling and prioritization of halogenated disinfection by-products in drinking water of China. 297 Environmental Science: Processes \& Impacts, 15(7), 1424-1429. 

research, 144, 482-490.

EPA. GAS, S. O. C. B. (2018). METHOD 8270E SEMIVOLATILE ORGANIC

https://archive.epa.gov/.../production/files/2015-12/documents/8270d...

304

Jiang, J., Han, J., \& Zhang, X. (2020). Nonhalogenated aromatic DBPs in drinking water chlorination: a gap between NOM and halogenated aromatic DBPs. Environmental science \& technology, 54(3), 1646-1656.

J. Jeong, J.Y. Kim, M. Cho, W. Choi, J. Yoon, Inactivation of Escherichia coli in the electrochemical disinfection process using a Pt anode, Chemosphere 67 (2007) 652-659.

Jeong, J., Kim, C., \& Yoon, J. (2009). The effect of electrode material on the generation of oxidants and microbial inactivation in the electrochemical disinfection processes. Water research, 43(4), 895-901.

Key, J. D. (2010). Development of a small-scale electro-chlorination system for rural water supplies (Doctoral dissertation).

Lapworth, D. J., Baran, N., Stuart, M. E., Manamsa, K., \& Talbot, J. (2015). Persistent and emerging micro-organic contaminants in Chalk groundwater of England and France. Environmental Pollution, 203, 214-225.

Laxmi Mohanta, V., Naz, A., \& Kumar Mishra, B. (2019). Distribution of heavy metals in the water, sediments, and fishes from Damodar river basin at steel city, India: a probabilistic risk assessment. Human and Ecological Risk Assessment: An International Journal, 26, 1-24. 
Ma, Q., Liu, T., Tang, T., Yin, H., \& Ai, S. (2011). Drinking water disinfection by heminmodified graphite felt and electrogenerated reactive oxygen species. Electrochimica acta, $56(24), 8278-8284$.

323 Mohanta, V. L., \& Mishra, B. K. (2020). Integration of cancer and non-cancer human health risk assessment for Aniline enriched groundwater: a fuzzy inference system-based approach. Environmental Geochemistry and Health, 1-17.

Mustapha, N.A., Liu, H., Ibrahim, A.O., Huang, Y., Liu, S., 2020. Degradation of aniline in groundwater by persulfate with natural subsurface sediment as the activator. Chem. Eng. J., 128078 https://doi.org/10.1016/j.cej.2020.128078.

Nielsen, D. M., \& Nielsen, G. (2006). The essential handbook of groundwater sampling. CRC 330 Press.

331 Norwitz, G., Kellher, P.N. (1981). Spectrophotometric determination of aniline by the diazotization-coupling method with N- (1-Naphthyl) ethylenediamine as the coupling agent. Anal. Chem. 53, 1238-1240. https://doi.org/10.1021/ac00231a025.

334 Otter, P., Mette, K., Wesch, R., Gerhardt, T., Krüger, F. M., Goldmaier, A., ... \& Grischek, T. 335 (2020).

336 Oxidation of Selected Trace Organic Compounds through the Combination of Inline Electro337 Chlorination with UV Radiation (UV/ECl2) as Alternative AOP for Decentralized Drinking 338 Water Treatment. Water, 12(11), 3275.

339 Pan, Y., \& Zhang, X. (2013). Four groups of new aromatic halogenated disinfection by340 products: effect of bromide concentration on their formation and speciation in chlorinated 341 drinking water. Environmental science \& technology, 47(3), 1265-1273. 
342 Pillai, I. M. S., \& Gupta, A. K. (2016). Anodic oxidation of coke oven wastewater: 343 multiparameter optimization for simultaneous removal of cyanide, COD and phenol. Journal 344 of Environmental Management, 176, 45-53.

345 Postigo, C., \& Barceló, D. (2015). Synthetic organic compounds and their transformation 346 products in groundwater: occurrence, fate, and mitigation. Science of the Total Environment, $347 \quad 503,32-47$.

348 Richardson, S.D., Postigo, C., 2015. Recent Advances in Disinfection By-products. American 349 Chemical Society, pp. 189e214

350 Särkkä, H., Bhatnagar, A., \& Sillanpää, M. (2015). Recent developments of electro-oxidation 351 in water treatment — a review. Journal of Electroanalytical Chemistry, 754, 46-56.

352 Sathish, M., \& Viswanath, R. P. (2005). Electrochemical degradation of aqueous phenols using 353 graphite electrode in a divided electrolytic cell. Korean Journal of Chemical Engineering, $354 \quad 22(3), 358-363$.

355 Singh, H., Sonal, S., \& Mishra, B. K. (2021). Understanding the toxicity effect and 356 mineralization efficiency of in-situ electrogenerated chlorine dioxide for the treatment of 357 priority pollutants of coking wastewater. Ecotoxicology and Environmental Safety, 211, 358111907.

359 Stuart, M., Lapworth, D., Crane, E., \& Hart, A. (2012). Review of risk from potential emerging 360 contaminants in UK groundwater. Science of the Total Environment, 416, 1-21.

361 Tasic, Z., Gupta, V. K., \& Antonijevic, M. M. (2014). The mechanism and kinetics of 362 degradation of phenolics in wastewaters using electrochemical oxidation. Int. J. Electrochem. 363 Sci, 9(7), 3473-3490. 
364 Tawabini, B. S., Plakas, K. V., Fraim, M., Safi, E., Oyehan, T., \& Karabelas, A. J. (2020). 365 Assessing the efficiency of a pilot-scale GDE/BDD electrochemical system in removing phenol 366 from high salinity waters. Chemosphere, 239, 124714.

367 USEPA. (2005). Guidelines for Carcinogen Risk Assessment, EPA/630/P-03/001F. Risk 368 Assessment Forum, Washington, DC. (Retrieved on March 2021).

369 USEPA. (2012). The drinking water standards and health advisories. Office of Water, US 370 Environmental Protection Agency, Washington, DC EPA 822-S-12-001 (Retrieved on March $3712021)$.

372 USEPA (2014). Priority pollutants list. Retrieved November 16,2001 from 373 https://www.epa.gov/sites/production/files/2015-09/documents/priority-pollutant-list374 epa.pdf/. (Retrieved on February 2021).

375 Villegas, L. G. C., Mashhadi, N., Chen, M., Mukherjee, D., Taylor, K. E., \& Biswas, N. (2016). 376 A short review of techniques for phenol removal from wastewater. Current Pollution Reports, $377 \quad 2(3), 157-167$.

378 Wen, Y. J., Yang, Y. S., Ren, H. J., Du, X. Q., Yang, X. Y., Zhang, L. Y., et al. (2015). 379 Chemical-biological hybrid reactive zones and their impact on biodiversity of remediation of 380 the nitrobenzene and aniline contaminated groundwater. Chemical Engineering Journal, 280, $381 \quad 233-240$.

382 Yi, J., Ahn, Y., Hong, M., Kim, G. H., Shabnam, N., Jeon, B., .. \& Kim, H. (2019). Comparison 383 between $\mathrm{OCl}-$-Injection and In Situ Electrochlorination in the Formation of Chlorate and 384 Perchlorate in Seawater. Applied Sciences, 9(2), 229. 
Figures

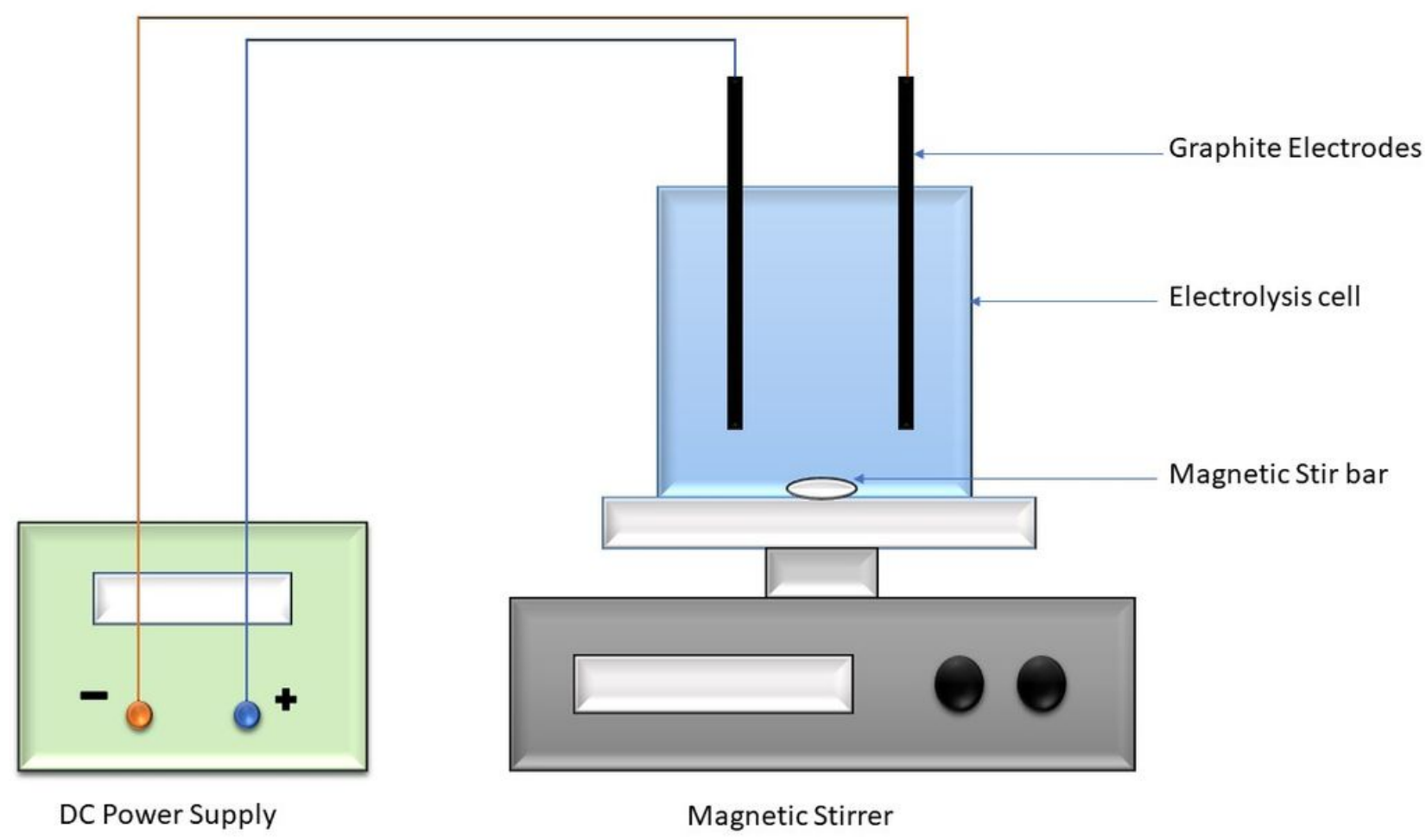

\section{Figure 1}

Schematic diagram of electro-chlorination set up.

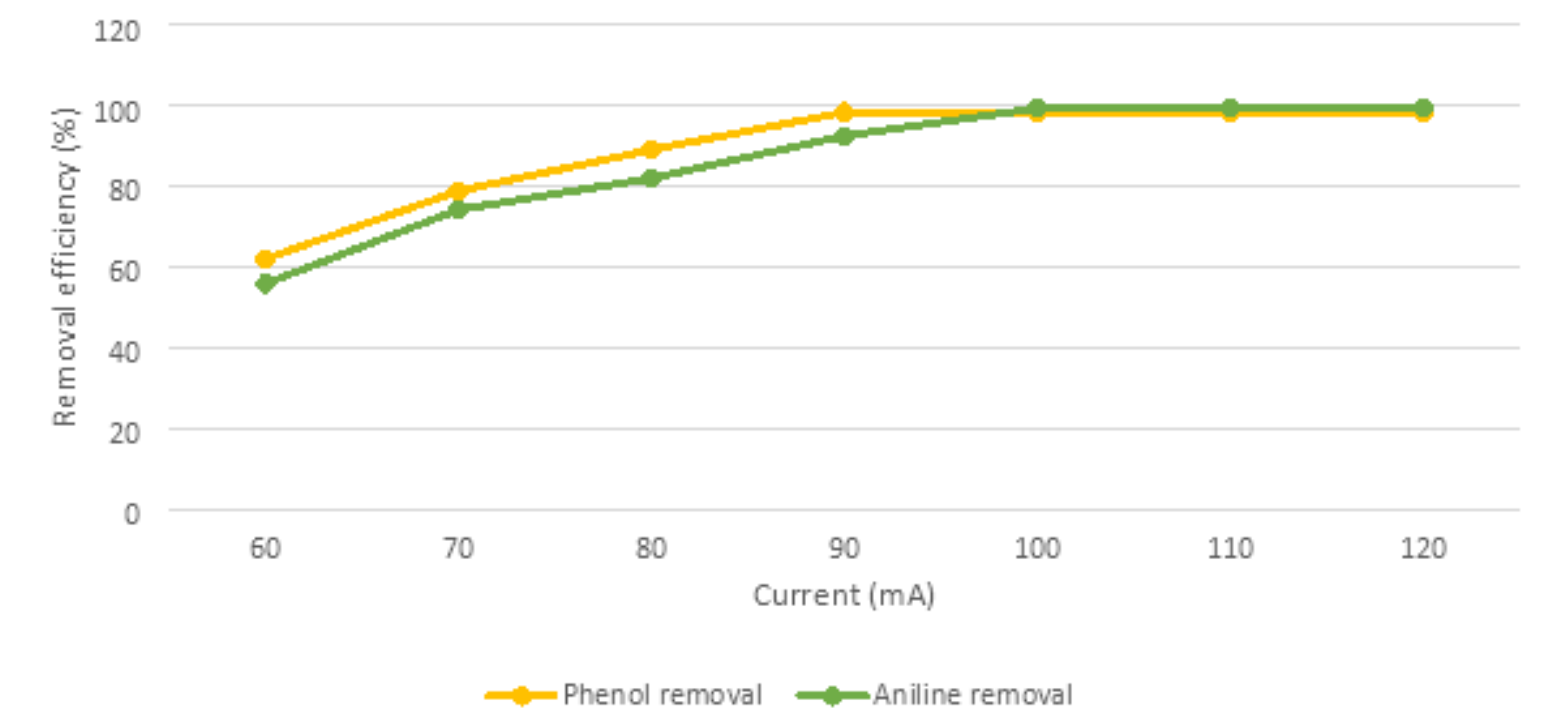

Figure 2

Removal efficiencies of phenol and aniline at different applied current 


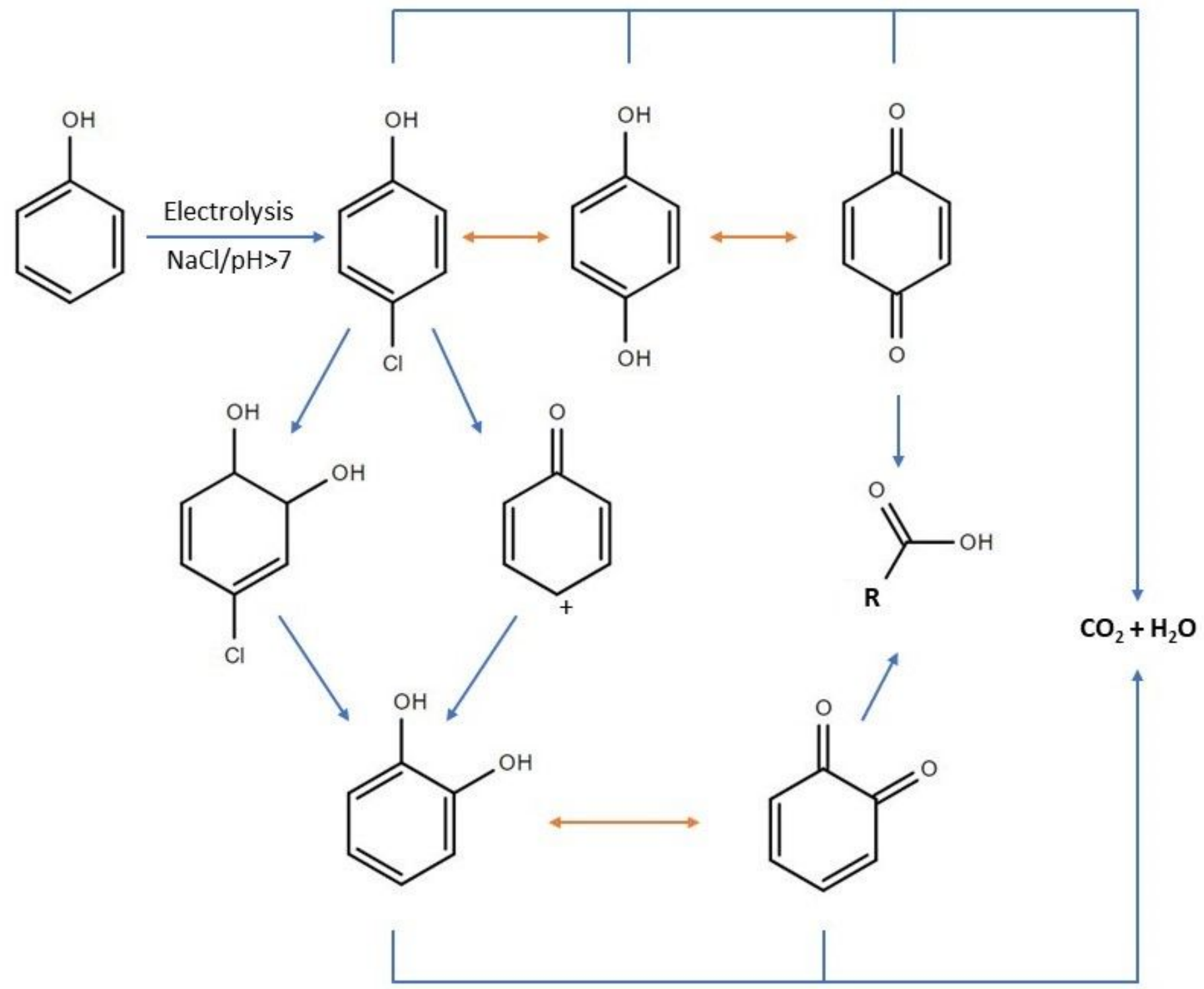

Figure 3

Pathway for decomposition of Phenol during Electrolysis with $\mathrm{NaCl}$ as electrolyte 


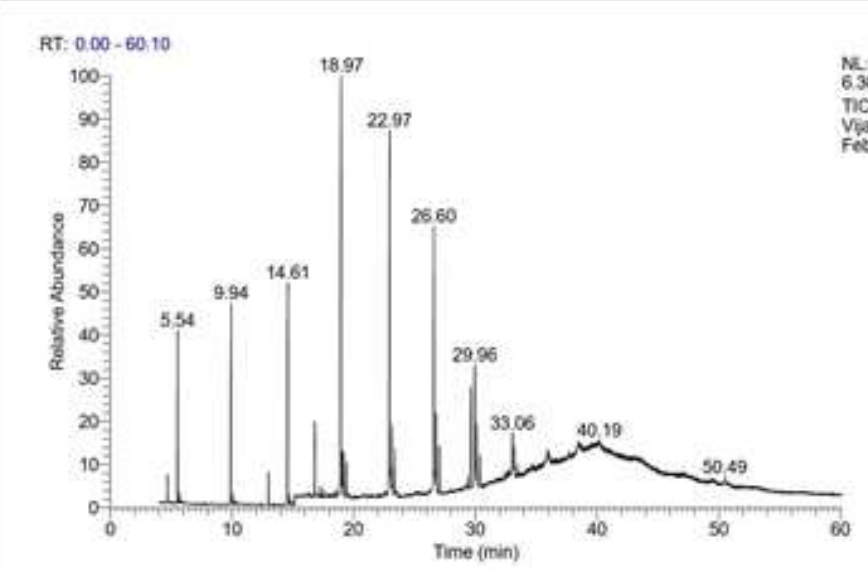

(a)

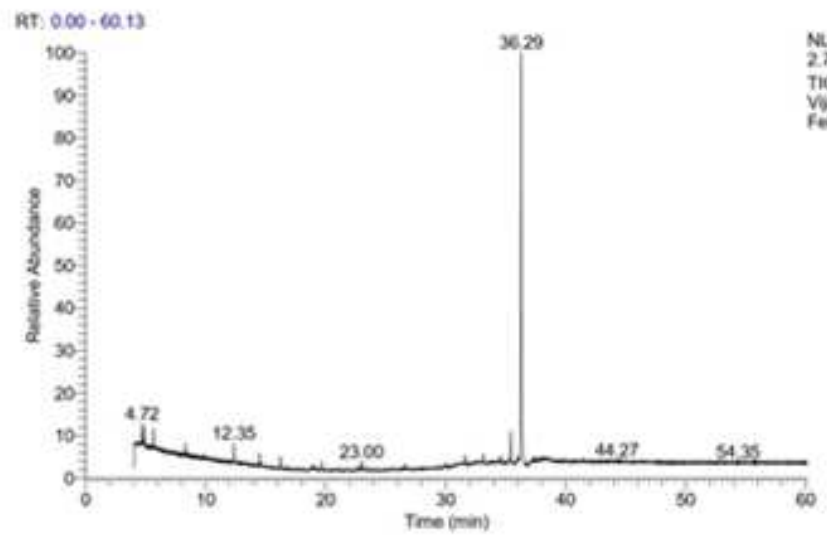

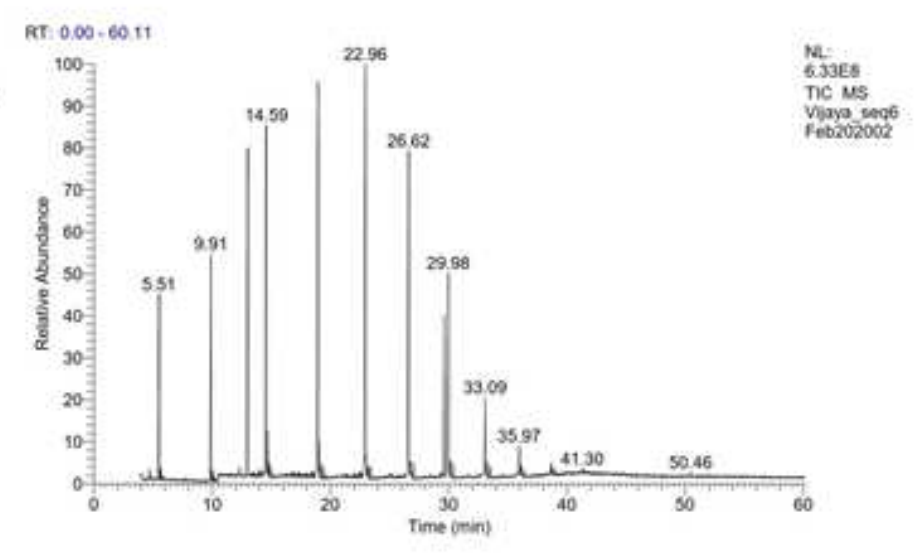

(b)

(c)

\section{Figure 4}

GC-MS analysis chromatograms (a) Raw groundwater (b) Ex-situ chlorinated water (c) In-situ electrochlorinated water 